\title{
Energetic analysis and optimisation of an integrated coal gasification-combined cycle power plant
}

\author{
E.E. Vlaswinkel \\ Department of Thermal Engineering, Twente University of Technology, P.O. Box 217, \\ 7500 AE Enschede (The Netherlands)
}

(Received August 8th, 1990; accepted June 11th, 1992)

\begin{abstract}
Methods are presented to analyse and optimise the energetic performance of integrated coal gasification-combined cycle (IGCC) power plants. The methods involve exergy analysis and pinch technology and can be used to identify key process parameters and to generate alternative design options for improved energetic efficiency. The methods are demonstrated by analysing the initial design of a $600 \mathrm{MW}_{\mathrm{e}}$ IGCC power plant based on the Shell coal gasification process.
\end{abstract}

\section{INTRODUCTION}

Since the nuclear power plants face a stalemate, it becomes clear that alternatives must be developed for the production of electricity.

Power plants using coal as a fuel are attractive for a number of reasons, such as the huge amount of coal feedstocks available in the world and the stability of the prices of coal. However, the use of coal as a fuel for power plants results in a number of environmental problems. Especially concerning the environmental aspect, integrated coal gasification-combined cycle (IGCC) power plants seem to offer many advantages over conventional coal-fired power plants.

An IGCC power plant is an integration of a coal gasification process, a gas-turbine and a steam cycle. Although each of these processes alone is technologically well understood, mutual integration influences the design and performance characteristics of each individual process. The energetic analysis and optimisation of an IGCC power plant is therefore a complicated problem.

In this paper methods are presented which can be used to analyse and optimise the energetic performance of IGCC power plants. Results are demonstrated

Correspondence to: Mr. E.E. Vlaswinkel, KSLA, Dept. EE-3, P.O. Box 3003, 1003 AA Amsterdam, The Netherlands. 
by analysing the initial design of a $600 \mathrm{MW}_{\mathrm{c}}$ IGCC power plant based on the Shell coal gasification process (SCGP).

\section{THE INTEGRATED COAL GASIFICATION COMBINED CYCLE}

Gasification is the complete conversion of coal to gaseous products. The gasification reaction can occur when an oxidant and coal is supplied to a gasifier. The fuel gas, mainly hydrogen and carbon monoxide, produced in the gasifier is after being cleaned, sent to a gas-turbine where it is burnt to produce electricity and hot flue gas. The hot flue gas is sent to a heat recovery steam generation section, where the heat in the flue gas is used to produce high pressure steam. The high pressure steam generated both in the gasifier and in the heat recovery steam generation section is sent to a steam turbine where additional electricity is generated.

IGCC power plants offer a number of advantages over conventional coal combustion power plants, i.e. [1]:

- reduced emission of pollutants;

- higher energy conversion efficiency;

- ability to accept a variety of coal feedstocks.

The most important disadvantage is the low level of experience. The preference of the electricity production companies in the Netherlands ('N.V. Samenwerkende Electriciteits-Productiebedrijven', SEP) to produce electricity in the future based on an environmentally acceptable, highly efficient coal feed process has resulted in the decision to build an IGCC demonstration power plant of $250 \mathrm{MW}_{\mathrm{e}}$ in Buggenum, The Netherlands.

Weighting factors as ability to accept a variety of coal feedstocks, plant performance, environmental acceptability, plant and maintenance costs and state of development, made SEP decide to base its IGCC demonstration power plant on the entrained-flow gasification process of Shell (Comprimo B.V., Amsterdam, 1987, [2]).

In order to gain insight in what the optimal process design will look like and which sub-processes have a significant influence on overall plant performance, an energetic analysis and optimisation study of an IGCC power plant has been performed. The reason to perform an energetic (instead of, for example, an economic) analysis and optimization of the power plant is that possible new insights will not be time-dependent. Whether or not these insights should be incorporated in future designs becomes clear in a total evaluation based on future time-dependent restraints, such as environmental and economical limitations.

\section{METHODS FOR ENERGETIC ANALYSIS AND OPTIMIZATION}

Although each of the three main processes of an IGCC power plant, a coal gasification process, a gas-turbine and a steam cycle, is well understood, the energetic analyses and optimization of an IGCC power plant remains a 
complicated problem due to mutual influences of each process on their design and performance.

In general a major feature of optimisation problems is that they are underdefined. In some cases, 'rules of thumb' can be used to eliminate certain process alternatives from further consideration, but in many cases this method finally results in an expensive and time-consuming thorough investigation of a number of alternative solutions. Also remains unknown whether and to what extent the finally chosen solution may be further optimized using future technologies or when installing more equipment, e.g. heat-exchangers.

Development of a methodology for analysing optimization problems may reduce the underdefined nature of the optimization problem. In the literature [3-5] a number of design methodologies have been developed and described. None of these methodologies attains the purpose of this study, although a number of elements can be fruitfully applied.

The methodology applied in this study involves the use of: (i) an exergy analysis, which indicates in a multi-component plant the plant irreversibility and its distribution among the plant components; and (ii) Linnhoff's pinch technology, which provides a means for optimal components integration resulting in a total energetic optimization of the plant.

Application of the exergy analysis and pinch technology is an iterative process (see Fig. 1), due to the mutual influences of the components on their efficiencies and on the overall plant efficiency.

\section{Exergy analysis}

An energy analysis, based on the first law of thermodynamics, considers all forms of energy as equivalent. An exergy analysis, based on both the first and second law of thermodynamics, is based on the concept of exergy, which can be defined as a universal measure of work potential, or quality of different forms of energy in relation to a given environment [8]. Associating the exergy with the three different forms of energy transfer taking place in control region analysis, i.e. work transfer, heat transfer, and stream of matter, is described by Kotas [6].

\section{Pinch technology}

Pinch technology, developed by Linnhoff $[7,8]$, is a method which, prior to any actual design being carried out, focuses on setting practical performance

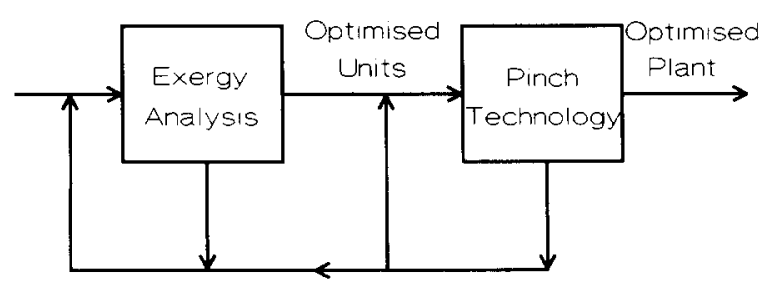

Fig. 1. Iterative application design methodology. 
targets, both for the achievable energy performance of a total system and the achievable number of heat transfer units.

For purpose of understanding the terminology used in this study some basic concepts of the pinch technology are described [9].

The streams in a process which have to be heated going from one unit to the other (cold streams), and the streams which have to be cooled (hot streams), can be represented on a temperature-enthalpy graph ( $T-H$ diagram) once their supply and target temperatures, their flow rates and physical properties are known (see the left side of Fig. 2).

Another presentation method is the 'Grand Composite Curve', which is the profile of the horizontal width between the curves when the curves in the $T-H$ diagram are brought together vertically to allow for a certain minimum temperature difference (right side of Fig. 2). It reveals where heat can be transferred between the process and external utilities, such as cooling and heating equipment, and between the sub-processes mutually.

\section{BASIC COMPONENTS OF THE SCGP POWER PLANT ANALYSED}

In order to interpret performance changes as the plant configurations or parameters are altered, a base case condition is defined in which the plant components, its configuration and its parameters are fixed.

The base case condition analysed in this paper concerns the initial design of a $600 \mathrm{MW}_{\mathrm{e}}$ IGCC power plant based on the Shell coal gasification process ${ }^{\circledR}$. Size, basic layout and process conditions of this plant corresponds to the IGCC power plant analysed in a study for the Dutch Ministry of Economic Affairs [10].

The plant is divided in a number of sub-processes or units, marked by dotted lines, as is shown in Fig. 3.
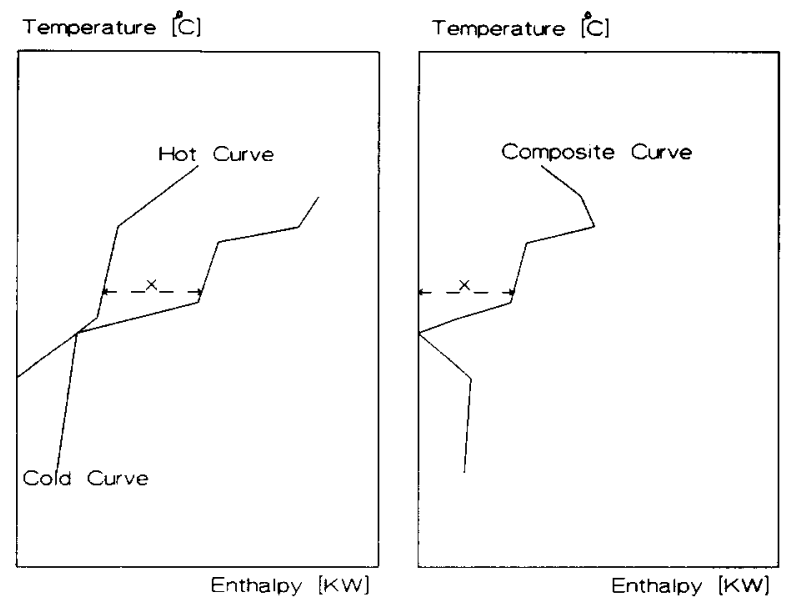

Fig. 2. T-H Diagram, and Grand Composite Curve. 


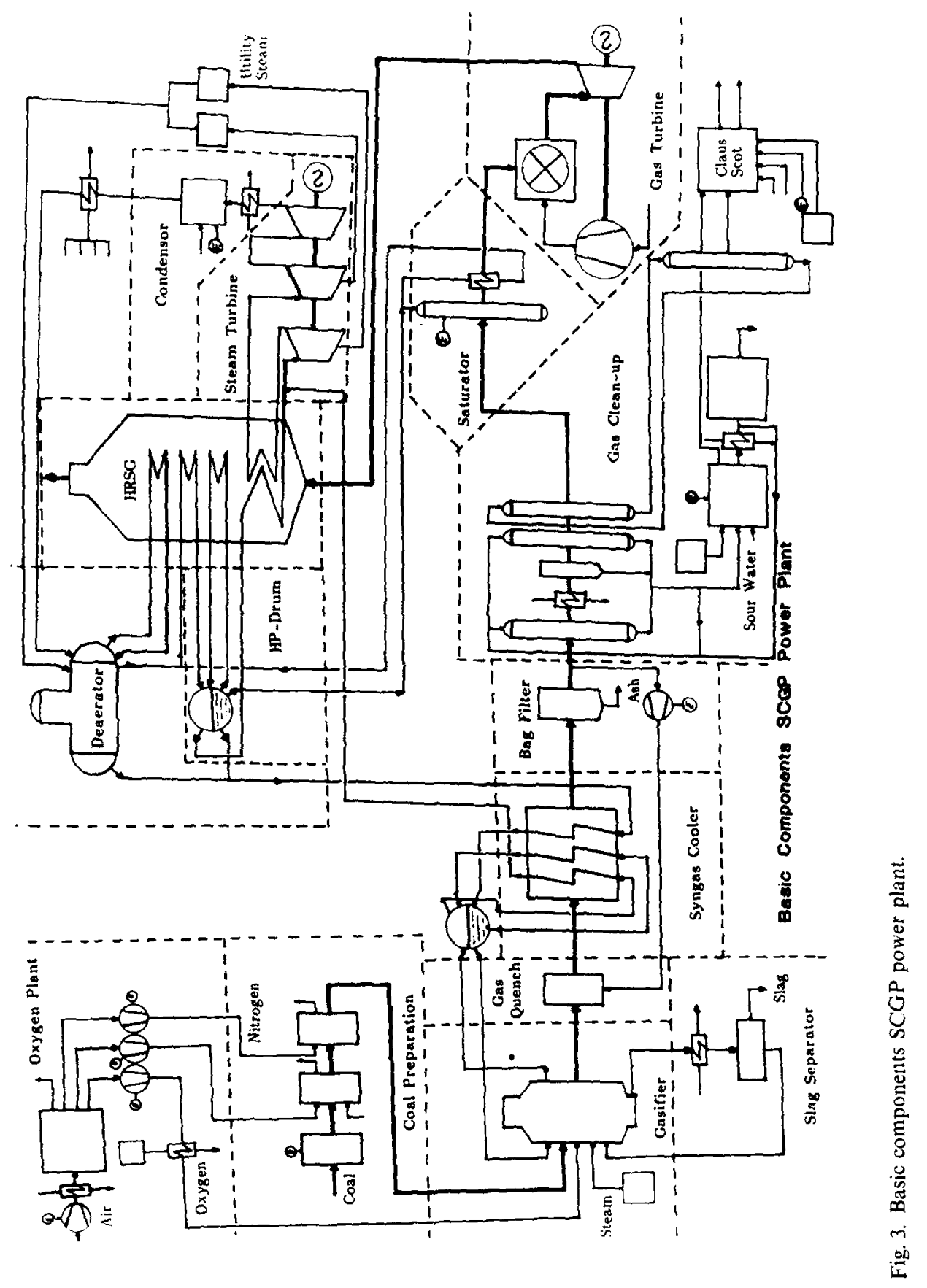


In the coal preparation unit the feed coal is finely ground and the coal surface moisture is reduced by burning natural gas. Coal transport takes place in a nitrogen atmosphere.

The air separation plant uses a cryogenic process producing $95 \%$ pure oxygen. The compressors have inter-coolers and are completely electric motor driven. The heat of compression is partly used to preheat condense water.

Dry coal with oxygen, and a small amount of high pressure steam, are fed into the gasifier which operates at 27 bara. The gasifier wall temperature is controlled by cooling coils in which saturated steam at 110 bara is generated. The fuel gas, mainly hydrogen and carbon monoxide, leaves the reactor at a temperature of $1450^{\circ} \mathrm{C}$.

About $60 \%$ of the ash in the coal is removed from the gasifier as slag in the slag separator. The slag is solidified into dense and glassy granules in a waterbath. Part of the available heat is used to preheat condense water.

To prevent sticky slag particles in the raw gas from sticking to the walls of the convective cooler, the raw gas is quenched by a recycle gas stream at a temperature of $230^{\circ} \mathrm{C}$. The quenched gas stream, with a temperature of $1075^{\circ} \mathrm{C}$, is sent to the convective cooler.

The convective cooler is used as superheater, evaporator and as economizer. The steam generated at 110 bara and superheated to $540^{\circ} \mathrm{C}$ is directly supplied to the high-pressure steam-turbine.

After leaving the syngas cooler at $230^{\circ} \mathrm{C}$, the cooled raw gas is directed to the bag filter unit where about $98 \%$ of the flyslag is separated. Part of the cleaned gas is used as quench gas. The remainder of the stripped gas is directed to the gas clean-up section.

The gas entering the gas clean-up section is humidified, cooled and stripped in a scrubber for solids, ammonia and soluble salts. Next, the gas is sent to a HCN scrubber and a sulfur removal system. The sulfur removal system utilizes an aqueous MDEA (Methyl DiEthanolAmine) solvent for $\mathrm{H}_{2} \mathrm{~S}$ absorption, and only operates properly at low temperatures. The clean fuel gas, containing five percent of the total sulfur in the feed coal, flows to the fuel gas saturator where the cold fuel gas is contacted with hot water. Transfer of moisture and heat takes place from the liquid stream to the gas stream. The fuel gas leaves the saturator with a moisture content of 29.6 volume percent and is, after further heating to $270^{\circ} \mathrm{C}$, sent to two General Electric MS $9001 \mathrm{~F}$ gas-turbines.

Both the fuel gas and air supplied by the compressor flow into the gasturbine combustion chamber. The hot gas exiting the combustion chamber is supplied to the gas-turbine expander which drives the compressor and the generator.

Each gas-turbine is coupled to a heat recovery steam generation (HRSG) section which recovers heat from the turbine flue gas. The HRSG section provides superheating of high pressure steam and reheating of intermediate pressure steam, supplements high pressure steam generation, preheats boiler feed water, and provides deaerator heating requirements. The flue gas enters the stack of the HRSG at $129^{\circ} \mathrm{C}$. 
The steam turbine is composed of high-pressure (HP $=110$ bara), intermediate-pressure (IP $=24$ bara) and low-pressure ( $\mathrm{LP}=6$ bara) power turbines. A portion of HP- and IP-steam is extracted from the HP- and IP-turbine and desuperheated to meet process steam requirements. The LP steam-turbine operates at a condensing back pressure of 0.05 bara.

In the surface condenser the exhaust steam from the LP power turbine condenses at 0.05 bara. The condense is then pumped to the deaerator.

The deaerator is a horizontal trayed unit which operates at 1.7 bara. Saturated conditions are maintained in the deaerator by addition of heat from the LP evaporator in the HRSG.

Support systems and services, such as water demineralization and instrumentation air, are provided.

\section{APPLICATION OF THE ENERGY OPTIMIZATION METHODS TO THE SCGP POWER PLANT}

Due to the limited available information about the design of the SCGP power plant, a large number of the mass and heat flows shown in Fig. 3 had to be calculated. A spreadsheet model has been developed which calculates both the mass and heat flows and simultaneously their exergy values, by solving the mass and heat balances of the different components. The spreadsheet model supplies also the necessary data for application of the pinch technology.

To reduce the amount of input data of the spreadsheet model the following five assumptions have been made:

(1) units operate adiabatically unless otherwise specified;

(2) kinetic energy differences are neglected;

(3) steam is assumed to be dry saturated;

(4) pressure losses are negligible unless otherwise specified.

\section{RESULTS OF THE EXERGY ANALYSIS OF THE SCGP}

The sub-processes of the total plant, presented in Fig 3, are numbered as follows for ease of presentation of the results:

1 Coal preparation unit

2 Oxygen plant unit

3 Gasifier unit

4 Slag separator unit

5 Gas quench unit

6 Syngas cooler unit

7 Bag filter unit

8 Gas clean-up unit

9 Saturator unit
10 Gas-turbine unit

11 HRSG unit

12 Steam-turbine unit

13 Condenser unit

14 HP-drum unit

15 Deaerator unit

16 General utility unit

17 Internal electricity consumption 

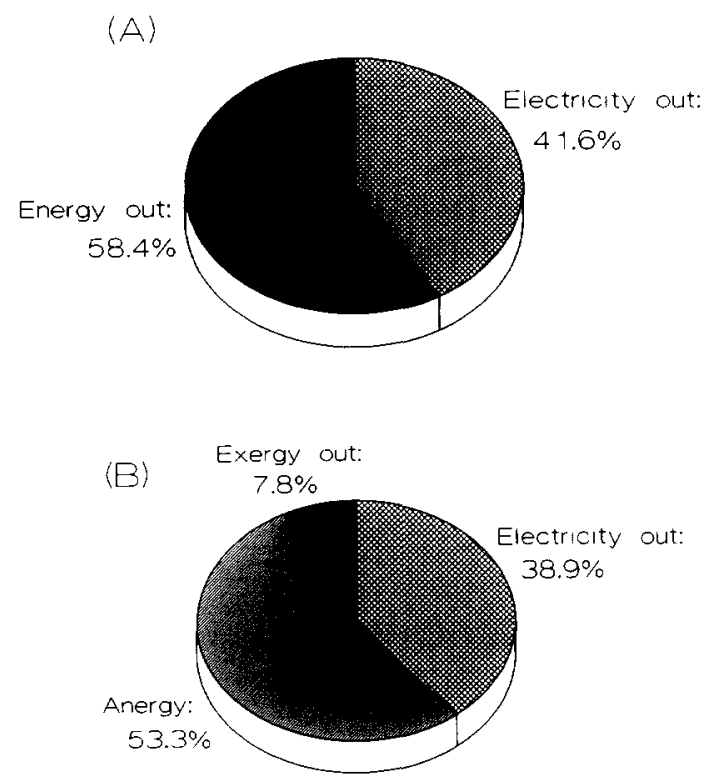

Fig. 4. Results of (A) energy and (B) exergy analysis of the total power plant.

Unit 16 represents small electricity consumers (e.g. effluent water treating, instrumentation air) not included in the foregoing units. Unit $\mathbf{1 7}$ is an imaginary unit which represents the total amount of electricity consumed by unit 1 up to and including 16.

It is stressed that the energetic and exergetic behaviour of all units, and of the total power plant, are given in percentages related to the total amount of energy respectively exergy supplied to the power plant.

Figure 4(A) shows the result of the energy analysis of the power plant. Presented are the electricity and the energy leaving the power plant in the form of heat or hot streams. The bottom figure presents the result of the exergy analysis of the power plant. Presented are the electricity exported, the exergy leaving the power plant in the form of heat or hot streams, and the anergy production or irreversibility.

The absolute values of the electricity leaving the power plant is the same in both balances but the relative values differ slightly because certain streams to the plant have a small amount of exergy but no energy (the exergy and energy of a certain stream are related to different infinite reservoirs).

The energy analysis shows that much energy is lost to the environment suggesting possibilities for improvement. However, the exergy analysis shows that only a relative small amount of exergy is lost to the environment (because the large amount of heat and hot streams leaving the plant are at relatively low temperature) and most of the exergy loss is due to irreversibilities. Figure 5 presents for each unit the energy leaving the unit to the environment, and the electricity produced. Figure 6 presents for each unit the exergy leaving the unit to the environment, and the electricity and anergy produced. 
Energy(heat) Electricity

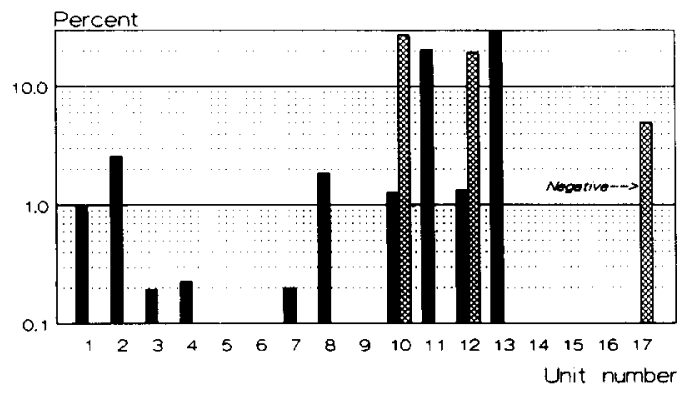

Fig. 5. Results energy analysis for each unit.

$\square$ Exergy(heat) $\square$ Anergy $\square$ Electricity

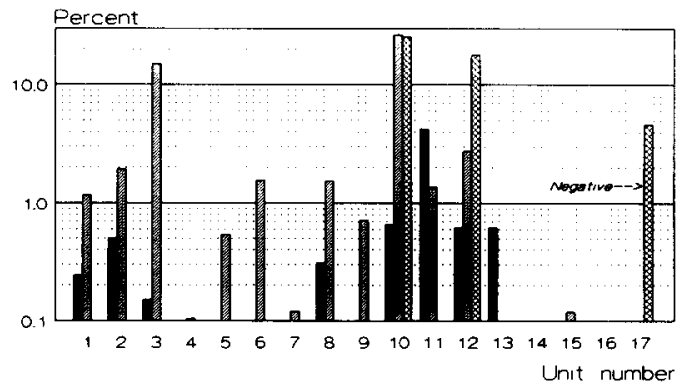

Fig. 6. Results exergy analysis for each unit.

The results of the energy and exergy analysis per subprocess unit are discussed in the following:

1 Coal preparation: Natural gas is burned in order to heat the LP nitrogen flow which is used to dry the coal. This is about $1 \%$ of the total amount of exergy supplied to the power plant. The burning of the natural gas (together with the exergy loss grinding the coal) results in an anergy production of the power plant of $1.2 \%$.

The SCGP requires that the feed coal must be finely ground ( -150 mesh) and the coal surface moisture must be reduced to low levels (about $3 \%$ by weight), in order to avoid problems of grinding or plugging in the coal transport lines and feed hoppers. The choice of the heat source to dry the coal has a large effect on overall plant performance because it influences the gasification process and therefore the distribution of the plant power generation between the gas-turbine and steam-turbine. Heat sources which can be used are steam, natural gas, fuel or flue gas. The choice for the drying system is influenced by the commercial status and performance of the system, and its capital and operating costs.

It is clear that the anergy production of this unit can be reduced if an internal hot stream is used for heating the nitrogen instead of an external 
utility. Direct usage of flue gas to dry the coal seems attractive, however, this stream contains a small amount of oxygen and should for reasons of safety be mixed with nitrogen.

2 Oxygen plant: The compressors in this unit consume a large amount of electricity which is partly converted to heat and are responsible for an anergy production of $1.9 \%$. The available heat from the compressors in the present design is $55.6 \mathrm{MW}$ at a temperature between $130^{\circ} \mathrm{C}$ and $40^{\circ} \mathrm{C}$. Only a small fraction is used. Utilization of the available heat may thus be improved.

The large electricity consumption of the oxygen plant is especially unwanted because electricity is the final product of the power plant. The absolute values of all losses in the sub-processes increase when the internal electricity consumption is compensated in order to produce the required amount of electricity.

At present cryogenic separation is the only commercial available technique for large scale oxygen production. The motive power for the compressors is for reason of simplicity usually provided by electric motors, although also steam/ gas turbines or fuel gas expanders can be used, which would reduce the anergy production in this unit.

A number of studies indicate that no significant performance or economic penalty exits associated with oxygen-blown versus air-blown IGCC systems. However, it is expected that the performance of oxygen-blown gasification systems will increase more than the air-blown systems by using the advanced gas-turbines. Therefore only an oxygen-blown system is considered in this study.

3 Gasifier: The anergy production in the gasifier is $15 \%$. The uncontrolled chemical reactions which take place here are inherently irreversible. The anergy production in the gasifier can, at present conditions, slightly be reduced by preheating the fuel and oxidant stream to the gasifier.

In the present design $99.7 \mathrm{MW}$ of heat is available at $1450^{\circ} \mathrm{C}$ due to the gasification reaction. In order to control the gasification temperature this heat is removed by generating high pressure steam at 110 bara. Other applications of this high temperature heat do not seem possible.

In general the performance of the total plant increases, and the irreversibility in the gasifier decreases, when the chemical energy (exergy) in the fuel gas increases due to modifications in the gasification process. A possible modification is decreasing the gasification temperature until the minimum value where still a stationary flow of slag is realized. This temperature depends on the type of coal being used and will be about $1250^{\circ} \mathrm{C}$.

The irreversibility in the gasification process can also be reduced by increasing the pressure. The exergy saved in this unit becomes available in the gasturbine. Increasing the gasification pressure will also introduce the possibility to install a fuel gas expander for extra power generation, although part of the extra power generated will be necessary to compress the fuel and the oxygen.

In general the gasifier conditions are determined by a number of aspects, like the requirements to produce a fuel gas with a stable combustion and to get a stationary flow of the slag, which limits the modifications on the gasification process. 
4 Slag separator: In the hot water/slag stream from the gasifier $14.5 \mathrm{MW}$ of heat is available between $200^{\circ} \mathrm{C}$ and $60^{\circ} \mathrm{C}$. In the present design only $75 \%$ is used, the remaining heat is rejected to cooling water. Utilization of the available heat may be improved by using it for example for preheating boiler feed water.

5 Gas quench: The anergy production in the gas quench (about $0.5 \%$ ) will be reduced when the temperature of the quench stream is raised.

The quench gas stream can be withdrawn from the main stream after the bag filter unit (small particles first have to be removed because they can damage the quench gas compressor), after the particle scrubber or after the sulfur removal section. When the gas stream is withdrawn early in the gas cleaning process, the power consumption of the quench gas compressor will increase due to the higher gas temperatures and consequently higher gas mass flows needed, but more high pressure steam can be generated in the syngas cooler and the capital expenses of the later steps in the gas clean-up section will reduce due to smaller gas flows. A high quench gas temperature can also be realized by heating the stream after the quench gas compressor. In this case also the mass flow of the quench stream will increase resulting in a larger amount of high pressure steam, however, also an extra heat exchanger has to be installed.

Instead of a gas quench also water/steam injection or a radiative cooler can be used to cool the synthesis gas. Water/steam injection is from an exergetic point of view unattractive. The use of a radiative cooler has the advantage compared to a gas quench cooler that the gas stream which has to be cleaned is reduced. The evaporated steam generated in the radiative cooler must be superheated in the convective cooler. However, this may cause problems at higher steam pressures (>90 bara, which are realistic in an integrated combined cycle system) if the radiative cooler generates a lot of steam as a result of a low heat of evaporation. The increasing amount of generated steam can possibly not be superheated anymore owing to a lack of heating capacity in the convective cooler. A solution is superheating steam in the radiative cooler. However, due to temperature variations and due to a high heat load, material and construction problems may occur. The main advantage of using a gas quench is that all the heat is rejected by the convective cooler, so that the choice of evaporation-to-superheating surface ratio is unconditioned.

6 Syngas cooler: The anergy production in the syngas cooler (1.6\%) will reduce when the heat exchange of the hot raw gas with the water/steam cycle is improved.

The steam generated in the syngas coolers and in the gasifier, is integrated with the steam generated in the HRSG section. For reason of simplicity the steam pressure produced in the convective cooler is usually the same as that of the steam produced in the HRSG unit. Other steam pressures are possible, however, this would result in extra complications, such as a separate steam entrance on the steam-turbine. The most likely steam pressures are therefore the fresh steam pressure or the reheated steam pressure in the HRSG boiler. Steam generation at the highest pressure produces the smallest amount of anergy, however, high temperatures may cause corrosion problems (the hot 
fuel gas contains a certain amount of acidic sulfur compounds). This is also the reason that superheated steam generation at $540^{\circ} \mathrm{C}$ in the convective cooler is still a subject of discussion.

7 Bag filter: The pressure drop of the fuel gas over the bag filter and the electricity consumption of the quench gas compressor results in a small anergy production $(0.1 \%)$. The dependence of this value on the layout and on the type of high temperature gas cooling process, is discussed before.

8 Gas clean-up: The anergy production in the gas clean-up section is $1.5 \%$ and the exergy loss to the environment $0.3 \%$. The exergy loss to the environment in reality may be a little higher at the expense of the anergy production because the sulfur stream leaving this unit is not taken into account. Nevertheless, it is an inescapable loss as sulfur removal is necessary from an environmental point of view.

In the present design only $40.5 \mathrm{MW}$ of the available $71.2 \mathrm{MW}$ of heat is used. The $71.2 \mathrm{MW}$ heat is available in the temperature interval from $230^{\circ} \mathrm{C}$ until $40^{\circ} \mathrm{C}$. The end-temperature of the steam production in the syngas cooler is set at $230^{\circ} \mathrm{C}$ with reference to expected corrosion problems at lower temperatures. The temperature of $40^{\circ} \mathrm{C}$ is set because only at low temperatures the sulfur (compounds) can be removed.

The introduction of high-temperature gas cleaning technologies, capable of removing halogens, sulfur compounds and small particles, will probably improve the process. It seems realistic to assume that in the future, processes working at $300-400^{\circ} \mathrm{C}$ will be available. Although a steam generation unit is still required (syngas cooler) first the available heat in the fuel gas to the gas-turbine is improved and secondly the total plant design is less complicated (introducing significant economic advantages) because no more cooling before desulfurisation and reheating prior to combustion is needed.

Prediction of the quantitative energetic improvement introducing hot fuel gas cleaning is difficult. The amount of steam generated in the syngas cooler will become smaller, however, also less utility steam is needed to preheat the fuel gas. Further the higher fuel gas temperature requires a larger amount of air supplied to the gas turbine in order to maintain the same combustion temperatures. This will result in a higher mass flow and therefore improve the performance of the gas turbine and will also increase the amount of steam which can be generated in the HRSG unit.

9 Saturator: The saturator loses no heat but the anergy production is $0.7 \%$, due to boiler feed water consumption for fuel gas moisturization and for preheating the saturated fuel gas.

Instead of boiler feed water for preheating the fuel gas also hot raw fuel gas before cleaning can theoretically be used. However, from a corrosion point of view this option is unattractive.

The addition of the boiler feed water as inert results in a shorter residence time of the combustion gases in the primary zone of the combustor, and a reduction of the peak combustion temperatures. As a consequence the thermal production of nitrogen oxide is reduced. After moisturization the saturated fuel gas must be further heated to prevent erosion from water drops on the gas-turbine blades. From an overall plant performance point of view the 
amount of boiler feed water added to the fuel gas should probably be as low as possible. Although fuel gas moisturization increases the mass flow through the gas-turbine and HRSG-unit, it also reduces the performance of the steam turbine, increases the exergy loss in the HRSG-unit, and increases the amount of boiler feed water to be prepared.

An alternative for fuel gas moisturization is nitrogen supply. Nitrogen is already available from the oxygen plant and can securely be heated, although it is more expensive to heat nitrogen than water. The effectiveness of nitrogen injection to steam is primary a function of the mutual heat capacities resulting in a 1.9 times higher mass flow of nitrogen compared to the mass flow of steam.

10 Gas-turbine: The total exergy supplied to the gas turbine is $1328 \mathrm{MW}$, of which $452 \mathrm{MW}$ is converted to electricity. The anergy production in the gasturbine is $471 \mathrm{MW}(26.6 \%)$. The combustion reactions taking place here are inherently irreversible. Improvements are mainly dependent on future gasturbine developments. A higher combustion temperature (and/or pressure) would theoretically reduce the anergy produced by transforming the chemical fuel energy to power, however, this option is limited by material strength and production of thermal nitrogen oxide.

If the temperatures of the air and fuel streams flowing into the combustion chamber are raised, the anergy production will reduce slightly. Raising the air temperature may in certain cases be possible but in the present design the temperature is already $380^{\circ} \mathrm{C}$ due to compression. Raising the temperature of the fuel gas above about $360^{\circ} \mathrm{C}$ is for reason of safety not acceptable because the hot fuel gas is mixed with air before entering the combustion chamber. Both options are therefore not applied in this study.

11 HRSG: The heat recovery steam generation unit has an exergy flow to the environment of $4.2 \%$ ( $74 \mathrm{MW}$ ). The exergy flow will be reduced when the temperature, or the amount, of the flue gas is lowered (presently $1273 \mathrm{~kg} / \mathrm{s}$, $132^{\circ} \mathrm{C}$ ) or the composition is changed (i.e. less evaporated water). Lowering the temperature may cause corrosion problems, due to the small amount of sulfur in the flue gas, resulting in a shorter span of life of the HRSG-unit. Whether this is acceptable, or not, and whether installation of more expensive more corrosive resistant materials can be justified, is an economic optimization problem.

The anergy production in the HRSG is 1.4 percent (24 MW) due to heat exchange between the hot flue gas and steam cycle over a finite temperature interval. Improvements are possible by optimizing the usage of the heat.

Firing a part of the coal or the fuel gas in the HRSG unit in order to improve the efficiency of the steam cycle (at the expensive of the power generated in the gas turbine) seems only attractive when gas-turbines are used with a low firing temperature. This option is not included in this study.

12 Steam-turbine: About $43 \%$ of the exergy supplied to the steam turbine leaves the unit as electricity $(19.3 \%)$. The anergy production in the steam turbine is $2.7 \%$ which can be reduced when steam is generated at higher pressures and temperatures.

The first option is limited by the diminishing return due to a smaller evaporation enthalpy, the second by increased material costs (above $570^{\circ} \mathrm{C}$ expensive austenitic steels have to be used). 
Alternative improvements are regenerative feed water heating in which case the low temperature heat in the flue gas should be used for other purposes than boiler feed water preheat, or steam reheating which is performed once already in the present design.

13 Condenser: The condenser loses a large amount of energy to the environment (478 MW), $28.9 \%$. The exergy loss is much smaller (11 MW), $0.6 \%$, and can only be reduced by lowering the condenser temperature by reducing the vacuum. This possibility is, however, rather limited due to the inlet temperature of the cooling water and the maximal acceptable cooling area of the condenser.

14 HP-drum: The HP-drum loses no heat. It is introduced to include the anergy production due to mixing of water- and steam-streams with different temperatures. The anergy production is $0.1 \%$.

15 Deaerator: The deaerator also loses no heat. The anergy production of $0.1 \%$ in this unit is due to mixing of streams with different temperatures.

16 General utility: This unit includes the electricity consumption in support units. The anergy production, due to conversion of electricity to heat, is $0.1 \%$. Exergy loss is negligible.

The imaginary unit if, representing the internal electricity consumption, is not elaborated upon since the electricity consumption of the sub-processes has (when significant) already been discussed above.

\section{Conclusion application exergy analysis}

The exergy analysis proves to be a useful tool to analyse and optimise the energetic performance of an IGCC power plant. In the IGCC power plant studied, the losses have been quantified and a number of possible improvements have been determined. It has become clear that the largest amount of exergy loss is due to internal irreversibilities: $53.7 \%$, while the exergy loss to the environment is $7.4 \%$.

The energy analysis on the other hand, contains little information in comparison with the exergy analysis. The information given by the energy analysis may even lead to wrong conclusions. The energy balance shows, for example, that a vast amount of energy is lost in the condenser, $28.9 \%$, suggesting splendid opportunities for improvement. However, the exergy balance shows that only $0.6 \%$ of exergy is lost which gives a more realistic view of the opportunity for improvement. Another example is the gas quench, where the energy analysis suggests no losses exist. The exergy analysis on the other hand pinpoints here the exergy loss or internal irreversibility.

Unit optimization by exergy analysis does not automatically result in an optimal overall plant performance. Decreasing the anergy production in a unit may result in an increase of the anergy production in other units. Some examples are:

(i) the change in overall efficiency of the power plant due to modifications of the gasifier conditions depends also on the resulting changes in exergy loss in the syngas cooler, the gas-turbine, the HRSG and the steam-turbine;

(ii) a lack of heat at the high pressure steam temperature may be solved by changing the temperature of the quench gas. However, it is as yet 
unclear whether this will outweigh the extra power consumption of the compressor;

(iii) although undoubtedly the introduction of high temperature gas cleaning reduces capital expenses, the improvement on overall plant efficiency is less straightforward because more electricity in the gas-turbine unit is produced while respectively less steam in the syngas cooler and more steam in the HRSG unit is generated;

(iv) increasing the feed temperatures of the reactants of the gas turbine increases its performance and makes it possible to increase the steam production in the HRSG unit, however, it is on first sight unclear if hot streams are available at the desired temperature;

(iv) utilization of the low temperature heat sources may be improved only then when heat sinks (cold streams) are available.

\section{RESULTS OF PINCH TECHNOLOGY ANALYSIS OF SCGP POWER PLANT}

The optimisation possibilities discussed before are gathered from unit analysis. However, in a multi-stage process the losses in the sub-processes are not mutually independent. Possibilities to optimise the total plant are analysed using the pinch technology.

Forbidden heat exchange matches in all following plant designs are avoided by creating the opportunity for a certain critical stream to exchange heat by an acceptable match. Fuel gas for example is not allowed to exchange heat in a heat exchanger with a stream containing an amount of oxygen for reasons of safety but may exchange heat with a steam or water stream.

The specific stream contributions to the temperature interval $\left(\Delta T_{\min }\right)$ between the different composite curves are:

- evaporating/condensing streams, which contribute $5^{\circ} \mathrm{C}$ to $\Delta T_{\min }$;

- liquid streams, which contribute for $7.5^{\circ} \mathrm{C}$ to $\Delta T_{\min }$;

- gas streams, which contribute for $10^{\circ} \mathrm{C}$ to $\Delta T_{\min }$.

This results for example in gas/gas heat exchangers working at a temperature difference of $20^{\circ} \mathrm{C}$.

\section{Basic configuration}

Figure 7 presents the grand composite curve of the basic design of the power plant. As mentioned introducing the pinch technology, reveals the grand composite curve where heat can be transferred between the process and the external utilities, and between the sub-processes mutually. The large surface between the left axis and the composite curve indicates the great amount of anergy production. Heat transfer takes place over large temperature intervals.

Some of the main heat sources and sinks of the power plant can be easily recognized, as there are: the gasification heat at $1450^{\circ} \mathrm{C}$, the heat due to burning natural gas at $1200^{\circ} \mathrm{C}$, the oblique lines representing the hot fuel gas in the syngas cooler and the hot flue gas in the HRSG, the horizontal line at $320^{\circ} \mathrm{C}$ representing the high pressure steam generation, and the lowest horizontal 


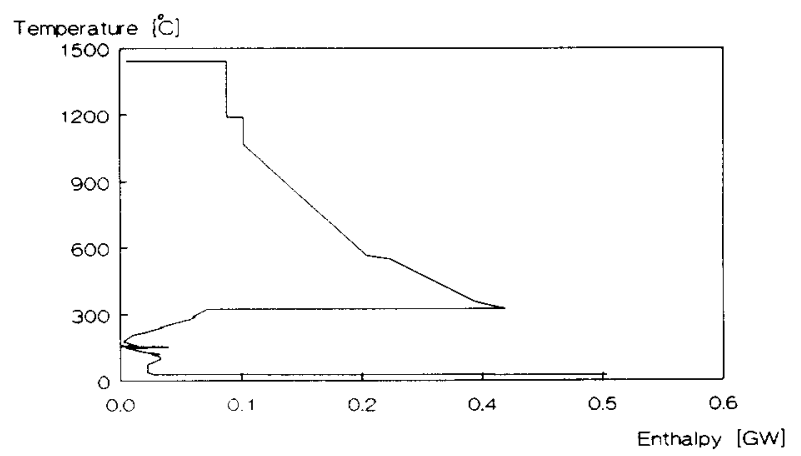

Fig. 7. Grand composite curve-base case configuration.

line representing the heat sent to the cooling water. Small fluctuations are representing smaller heat sources and sinks, as there are heat of the compressors or preheating the fuel gas for the gas-turbine.

The total power plant needs a small amount of hot utility due to neglecting some minor hot streams for this study and due to the assumed stream contributions to the temperature intervals. The plant needs a lot of cold utility (cooling water) which represents the heat loss to the environment.

Part of the evaporation section (the horizontal line at $320^{\circ} \mathrm{C}$ ) achieves heat from the gasifier and should therefore be placed below the gasification line at $1450^{\circ} \mathrm{C}$. This will not introduce impossible heat exchanges in this or plant designs and for reason of simplicity the present presentation will be maintained.

The performance of the basic design of the power plant is:

- Electricity produced $=$ Gas-turbine + Steam-turbine + Electricity consumed

$$
=452.9 \mathrm{MW}+305.2 \mathrm{MW}-83.1 \mathrm{MW}=675.0 \mathrm{MW}
$$

- Fuel supplied $=$ Coal + Natural gas $=1605.3 \mathrm{MW}+16.6 \mathrm{MW}=1621.9 \mathrm{MW}$

- Efficiency $=41.62 \%$

In order to gain insight in how the energetic efficiency of the base case design can be improved the total power plant is rebuilt step by step.

\section{Base configuration excluding natural gas burning}

It is assumed that the steam cycle is working at a pressure of 110 bara (just as in the base case) and contains one reheater section. Application of a reheater section is attractive because of the large amount of high temperature heat available.

The following plant contains all the heat sources and necessary heat sinks available in the present design, except the burning of natural gas. The amount of boiler feed water in the steam cycle is $250 \mathrm{~kg} / \mathrm{s}$, but due to internal consumption only $206 \mathrm{~kg} / \mathrm{s}$ of steam is superheated (in the base case design $220 \mathrm{~kg} / \mathrm{s}$ of steam is superheated). Figure 8 presents the grand composite curve. The performance of this design is: 


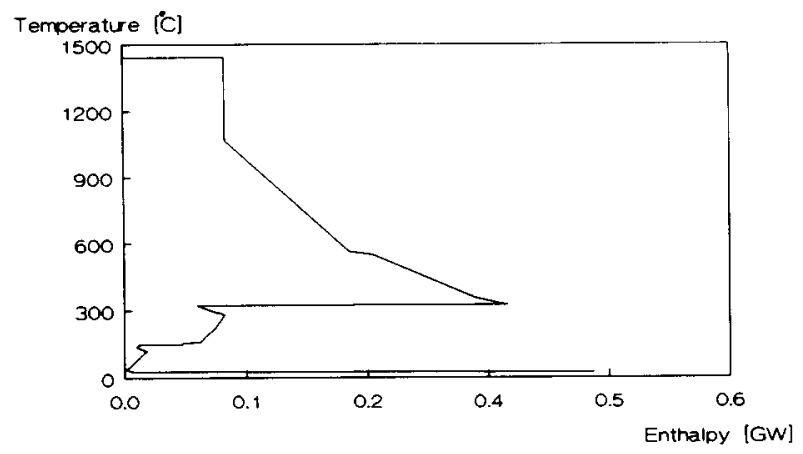

Fig. 8. Grand composite curve-base case configuration excluding natural gas.

- Electricity produced $=$ Gas-turbine + Steam-turbine + Electricity consumed $=452.9 \mathrm{MW}+287.9 \mathrm{MW}-83.1 \mathrm{MW}=657.7 \mathrm{MW}$

- Fuel supplied $=$ Coal $=1605.3 \mathrm{MW}$

- Efficiency $=40.97 \%$

The efficiency of the plant without natural gas burning is lower than the efficiency of the base case design. Comparison of Figs. 7 and 8 shows the inefficient use of high temperature heat in the present design. The efficiency of the plant will increase when the utilization of high temperature heat is improved by introducing utility steam for the low temperature cold streams.

\section{Base configuration extended with utility steam}

Figure 9 presents the grand composite curve of the plant with utility steam. All the heat, available at a temperature where it is possible to generate high pressure steam is used for this purpose. Low temperature heat sources have to be introduced in order to supply cold streams. The amount of superheated steam is $235 \mathrm{~kg} / \mathrm{s}$, which is $29 \mathrm{~kg} / \mathrm{s}$ more than in the foregoing design. Not all this steam can be completely expanded in the steam-turbine because $19.4 \mathrm{~kg} / \mathrm{s}$ of 22 bara steam, $22.1 \mathrm{~kg} / \mathrm{s}$ of 6 bara steam and finally $10.5 \mathrm{~kg} / \mathrm{s}$ of 1.2 bara steam has to be used as utility steam. The area under the grand composite curve has been reduced (so the anergy production is lowered). The performance of this design is:

- Electricity produced $=$ Gas-turbine + Steam-turbine + Electricity consumed

$$
=452.9 \mathrm{MW}+311.8 \mathrm{MW}-83.1 \mathrm{MW}=681.6 \mathrm{MW}
$$

- Fuel supplied $=\mathrm{Coal}=1605.3 \mathrm{MW}$

- Efficiency $=42.46 \%$

This is a significant improvement compared to the present plant which could be expected because this highly integrated plant uses all available heat from the air compressors, the slag separation unit, etcetera, at the highest possible temperature level. This design might be too expensive to realise in practice. But foregoing clearly shows what the effect of process integration on the plant efficiency can be. 


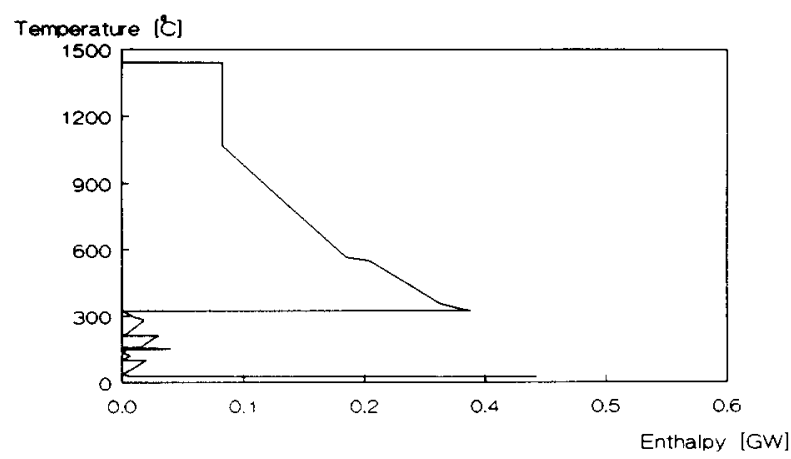

Fig. 9. Grand composite curve-base case configuration extended with utility steam.

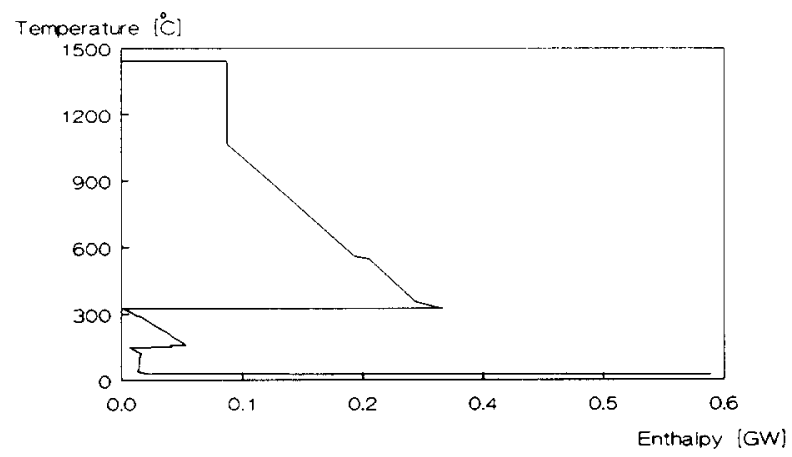

Fig. 10. Grand composite curve-base case configuration with extensive integration.

Base configuration extended with results exergy analysis

Application of the exergy analysis indicated a number of possibilities to improve the overall performance of the plant. Introduction of some results: - preheat the oxygen stream supplied to the gasifier until $205^{\circ} \mathrm{C}$;

- preheat the coal stream supplied to the gasifier until $173^{\circ} \mathrm{C}$;

- preheat the quench gas stream until $300^{\circ} \mathrm{C}$;

- use of nitrogen in order to reduce the $\mathrm{NO}_{x}$ emission of the gas-turbine;

- preheat the nitrogen stream until $300^{\circ} \mathrm{C}$.

The assumption is made that the oxygen and coal supplied to the gasifier are preheated by steam. Minimizing the exergy loss due to steam consumption and maximizing the extra amount of high pressure steam generated in the gasifier (as a result of the extra heat supply) results in the preheated target temperatures for these streams. Comparing Fig. 10 with 9 shows the slightly higher amount of heat available at $1450^{\circ} \mathrm{C}$ which can be used to generate extra high pressure steam at the expense of low temperature heat used to preheat the oxygen and coal stream.

It is further assumed that quench gas and nitrogen gas are preheated by steam to avoid expensive gas-gas heat exchangers. The increase in temperature 
of the quench gas stream results in a higher gas mass flow through the syngas cooler. This results in a slightly less steep oblique line in Fig. 10 compared to Fig. 9. In addition extra high pressure steam can be generated.

Changing steam moisturization to nitrogen supply reduces the steam consumption and therefore increases the electricity production of the steam turbine; changes the amount of power generated by the gas-turbine expander and the power consumed by the compressor; raises the mass flow through the HRSG and reduces the amount of evaporated water in the flue gas and so reduces the exergy loss of the HRSG section to the environment, and increases the electricity consumption of the nitrogen compressors and the amount of low temperature heat due to the installation of the nitrogen compressor.

The amount of superheated steam generated in this design is $252 \mathrm{~kg} / \mathrm{s}$. No utility steam is needed as already enough low temperature heat is available. The performance of this design is:

- Electricity produced $=$ Gas-turbine + Steam-turbine + Electricity consumed

$$
=449.5 \mathrm{MW}+353.9 \mathrm{MW}-112.9 \mathrm{MW}=690.5 \mathrm{MW}
$$

- Fuel supplied $=\mathrm{Coal}=1605.3 \mathrm{MW}$

- Efficiency $=43.01 \%$

Again this is an improvement compared to the foregoing plant design.

\section{Base configuration extended with low pressure steam cycle}

The grand composite curve in Fig. 10 shows a lot of anergy production in the low temperature region. Introducing a low pressure steam generation cycle would reduce this loss and improve the efficiency. Figure 11 presents the grand composite curve, of the plant similar to the foregoing one but with installation of a LP steam cycle.

The low pressure steam cycle is chosen to work at 20 bara at a superheat temperature of $330^{\circ} \mathrm{C}$. Generating low pressure steam at 20 bara $(20.5 \mathrm{~kg} / \mathrm{s})$ also introduces the necessity to supply utility steam at 7 bara. This results in the following performance:

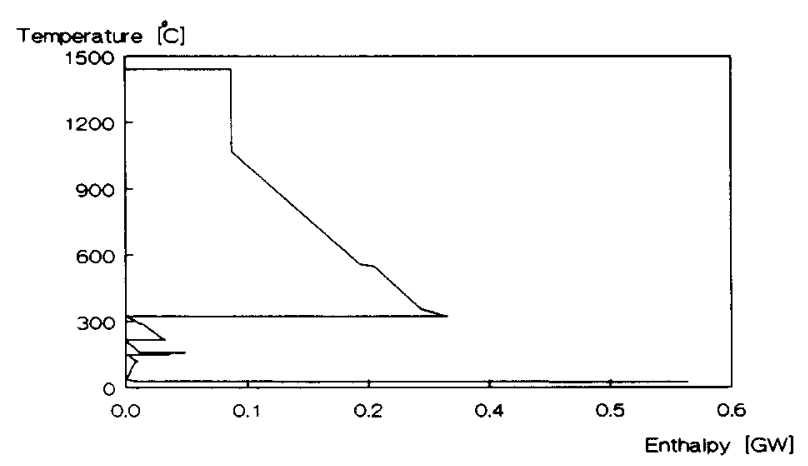

Fig. 11. Grand composite curve-base case configuration with extensive integration and utility steam. 
- Electricity produced $=$ Gas-turbine + Steam-turbine + Electricity consumed

$$
=449.5 \mathrm{MW}+360.2 \mathrm{MW}-113.0 \mathrm{MW}=697.7 \mathrm{MW}
$$

- Fuel supplied $=\mathrm{Coal}=1605.3 \mathrm{MW}$

- Efficiency $=43.40 \%$

This is the highest efficiency achieved in this study.

\section{Conclusion application pinch technology}

Pinch technology proves to be a useful tool to analyse and optimise the energetic performance of an IGCC power plant. The IGCC power plant studied has potential to achieve a high energetic performance if properly integrated. This can easily be done by using the pinch technology.

In the analysis of the previous section, only a few insights gained from the exergy analysis have been applied, and more or less "non-proven" technologies have not been studied at all. Also the influence of small hot and cold streams have not been studied. However, the present plant designs can be further developed by using the same methodology as applied in this study.

Future limitations, based on economical or environmental argumentations, and their influences can easily be introduced respectively quantitatively be predicted by the exergy analysis and pinch technology. This will introduce an extra iteration step in the suggested design methodology as presented in Fig. 1.

To gain deeper insight whether all matches are possible and are not forbidden, further study of the most attractive design is possible. A network design procedure is already included in the pinch technology and can suitably be applied. Finally the dynamic behaviour of the most promising design can be studied by using flowsheeting programs.

\section{GENERAL CONCLUSIONS}

Exergy analysis in combination with pinch technology is a fruitful methodology to analyse and optimise the energetic performance of an IGCC power plant.

A number of possible improvements on the IGCC power plant discussed in this study, have been suggested and the quantitative influences on overall plant performance have been calculated.

The IGCC power plant studied has a large potential for energetic optimisation by minimising the internal irreversibilities and optimising heat integration.

\section{ACKNOWLEDGEMENTS}

The author wishes to thank the department of Thermal Engineering of the University of Twente, especially Prof. Dr. Ir. J.J.H. Brouwers who has also been helpful in establishing this publication, and the Electricity Production 
Company for the East and North of the Netherlands (E.P.O.N.), for the possibility they have offered to perform and complete foregoing study and allowing publication.

\section{REFERENCES}

1 Penner, S.S., 1987. Coal gasification: Direct applications and synthesis of chemicals and fuels. Energy Int. J., 12: 623-903.

2 Comprimo B.V., 1987. Electricity from coal - Coal combustion or gasification, Study for the N.V. Samenwerkende Electriciteits-Productiebedrijven, Amsterdam, 1987 (in Dutch).

3 Douglas, J.M., 1988. Conceptual Design of chemical processes. McGraw-Hill, New York.

4 Westerberg, A.W. and Hutchinson, H.P., Motard, R.L. and Winter, P., 1979. Process Flowsheeting. Cambridge University Press, Cambridge.

5 Kumar, A., 1981. Chemical process synthesis and engineering design. McGraw-Hill, New York, NY.

6 Kotas, T.J., 1985. Exergy method of thermal plant analysis. Butterworth, London.

7 Townsend, D.W. and Linnhoff, B., 1983. Heat and power networks in process design AIChE J., 29 (5): 742-771.

8 Tjoe, T.N. and Linnhoff, B., 1986. Using pinch technology for process retrofit. Chem. Eng. 28 (april): $47-60$.

9 Linnhoff, B. and Townsend, D.W., Boland, D., Hewitt, G.F., Thomas, B.E.A., Guy, A.R., and Marsland, R.M., 1982. Process Integration for the efficient use of energy. Pergamon Press, Oxford.

10 Fluor Daniel, B.V., Haarlem, 1987. Integrated coal gasification combined cycle power plant study. Study for the Dutch Ministry of Economic Affairs, The Hague, The Netherlands.

11 Fratzscer, W. and Beyer, J., 1981. Stand und Tendenzen bei der Anwendung und Weiterentwicklung des Exergiebegriffs. Chem. Tech., 33 (1): 1-10 (in German). 